In view of these findings it was, therefore, accepted that the occurrence of these tumours was not the result of the experimental procedures.

It has been demonstrated that it is possible to produce tumours which appear to be arising from the mesothelial cells of the pleura by inoculating certain dusts into the pleural cavities of rats. One further tumour was obtained by exposing an animal to an asbestos dust cloud. The fact that these neoplasms were produced by silica and chrysotile asbestos as well as crocidolite fibre complicates the interpretation of these preliminary observations, and indicates the need for further investigations.

I thank members of the Unit who assisted in this experiment, those who provided the dust samples used, and especially Dr. H. Palmhert and Mary Hart, who helped in the animal inoculations.

Pneumoconiosis Research Unit of the Council for Scientific and Industrial Research, Johannesburg.

* Present address: Pneumoconiosis Research Unit, Llandough Hospital, Llandough, Penarth, Glamorganshire.

Wagner, J. C., Sleggs, C. A., and Marchand, P., Brit. J. Indust. Med. $17,260(1960)$.

${ }^{2}$ Sleggs, C. A., Marchand, P., and Wagner, J. C., S. Afr. Med. J., 35 , $28(1961)$.

${ }^{3}$ Harington, J. S., Nature, 193, 43 (1962)

4 Ratcliffe, H. I., Amer. J. Path., 16, 237 (1940)

${ }^{6}$ Wagner, J. C., Munday, D. E., and Harington, J. S., J. Path. Bact., 84,73 (1962)

\section{An Early Test for Possible Skin Carcinogens \\ in the Mouse : Effect of Different Doses of 3-Methylcholanthrene in Benzene Solution}

AN early test for possible skin carcinogens in the mouse has been reported ${ }^{1,2}$. The test is based on a tetrazolium reduction method. It was demonstrated that the test could reveal the carcinogens in a blind test of 21 substances of which 7 were carcinogens.

The present communication gives the values obtained with different doses of 3-methylcholanthrene in benzene solution applied to a circumscribed area of the skin of hairless mice. The results are given in Table 1.

Table 1. Tetrazoutum Test with Different Doses of 3-MethylCHOLANTHRENE

$\begin{array}{cccc}\mu \mathrm{g} \text { applied } & \begin{array}{c}\text { \% solution } \\ \text { in benzene }\end{array} & \text { No. of mice } & \text { Test result } \\ 0 \cdot 4 & 1 / 128 & 16 & 0 \cdot 898 \\ 0 \cdot 8 & 1 / 64 & 16 & 0 \cdot 792 \\ 1 \cdot 6 & 1 / 32 & 16 & 0 \cdot 818 \\ 3 \cdot 1 & 1 / 16 & 32 & 1 \cdot 107 \\ 6 \cdot 3 & 1 / 8 & 32 & 1 \cdot 168 \\ 25 \cdot 0 & 1 / 2 & 32 & 1 \cdot 361 \\ 50 \cdot 0 & 1 / 1 & 16 & 1 \cdot 410\end{array}$

Terracini, Shubik and Della Porta ${ }^{3}$ found a step-like increase in the tumour yield after single applications to mouse skin of different doses of DMBA. Studies are in progress at our Institute to find out if such a step exists for hairless mice exposed to single applications of 3-methylcholanthrene. The preliminary results ten months after the single painting are shown in Table 2 .

Table 2. Skin Papiliomata occurring Ten Months aFTer a Single SURFACE APPLICATION OF 3-MrYHYLCHOLANTHREN IN BENZENE 'TO

$\%$ solution
$1 / 64$
$1 / 32$
$1 / 16$
$1 / 8$
$1 / 1$

No. of mice Papillomata

30
30
30
30
30

These results demonstrate that such a well-known carcinogen as 3-methylcholanthrene gives negative results with the tetrazolium test when very small doses are given. The testing of unknown substances should therefore be performed with relatively strong, but non-ulcerative, doses. The possible specificity of the test, however, is given some further support by the preliminary results reported in Table 2. These seem to be in accordance with the conclusion of Terracini, Shubik and Della Porta": "A critical dose level exists at which single application of carcinogens becomes fully effective",

Otav HILMAR IVERSEN

Institutt for Generell og Eksperimentell Patologi,

Universitetet i Oslo.

${ }^{1}$ Iversen, O. H., Nature, 192, 273 (1961).

${ }^{2}$ Iversen, O. H., and Evensen, A., Acta Path. and Microbiol. Scand., Supp. $156(1962)$.

${ }^{8}$ Terracini, B., Shubik, Ph., and Della Porta, G., Cancer Res., 20 $1538(1960)$.

\section{Mineral Phase in Osteoporotic Bone}

IN a survey of the incidence of fractures ${ }^{1}$, particularly those of the head and neck of the femur, expressed in terms of population at risk, the distribution found made it quite clear that some must be of pathological origin. Such bones appear osteoporotic, and there has been a widespread assumption that the tissue component at fault is the calcium phosphate.

Should a change occur in the mineral, or in the calcium-and phosphate-ievel of its surroundings, one would expect to find changes in composition. Traditional methods of chemical analysis for calcium and phosphate cannot be profitably used, because the main need is to distinguish between a number of closely related calcium phosphates which might be present as mixtures. A further complication is that the mineral crystallites in bone have a very large surface area, so that adsorbed ions could produce misleading results. At present the most sensitive method for demonstrating individual components, which can be interpreted unambiguously, is X-ray diffraction.

A satisfactory method for distinguishing the various ealcium phosphates involves taking photographs at room temperature, and then after heating to $1,000^{\circ} \mathrm{C}$ (ref. 2). At room temperature possible compounds are hydroxyapatite, octacalcium phosphate, monetite, brushite and calcium carbonate. After heating: apatite remains as apatite; apatite mixed with the other calcium phosphates, or apatite with phosphate adsorbed on to the crystal surfaces, reacts to form $\beta$-tricalcium phosphate, the proportion depending on the amount of excess phosphate present; calcium carbonate is transformed into calcium oxide.

One example where a difference is known in the tissue fluids surrounding the mineral in bone is in infants. These children have a higher serum phosphate than older children and adults. X-ray diffraction examination of bone from infants gave the hydroxyapatite pattern when unheated, and hydroxy apatite mixed with a littlo $\beta$-tricalcium phosphate after heating. Bones from the older age-groups gave hydroxyapatite only. In this case the different ionic concentrations in the surrounding fluids have been mirrored in the mineral composition.

To investigate possible differences in the mineral composition in osteoporotic bone the upper ends of the femur were used. At least three separate sub. 